\title{
DAYA HAMBAT OBAT KUMUR CETYLPYRIDINIUM CHLORIDE DAN OBAT KUMUR DAUN SIRIH TERHADAP PERTUMBUHAN STREPTOCOCCUS MUTANS
}

\author{
${ }^{1}$ Amelia I. Toar \\ ${ }^{2}$ Jimmy Posangi \\ ${ }^{3}$ Vonny Wowor \\ ${ }^{1}$ Kandidat Skripsi Program Studi Kedokteran Gigi Fakultas Kedokteran \\ Universitas Sam Ratulangi Manado \\ ${ }^{2}$ Bagian Farmakologi Fakultas Kedokteran Universitas Sam Ratulangi Manado \\ ${ }^{3}$ Program Studi Kedokteran Gigi Fakultas Kedokteran Universitas Sam Ratulangi Manado \\ E-mail: ilonetoar@gmail.com
}

\begin{abstract}
Dental caries and periodontal diseases are still the major problems of oral health among the community. The microbes Streptococcus mutans that accumulate in plaques have an important role in the occurences of these two diseases. The control of plaque forming can be done chemically by using mouthwash. Cetylpyridinium chloride (CPC) and betle leaf (Piper betle Linn.), among others, are active ingredients that are added in the preparation of alcohol-free mouthwash. This study aimed to determine whether there was a difference between the inhibition of alcohol-free mouthwash containing CPC, and betle-leaf mouthwash to the growth of $S$. mutans. This was an experimental study with a post-test-only controlgroup design. The technique for testing inhibition used the Kirby Baurer disc diffusion method with samples of cultures of $S$. mutans The trial materials were commercial alcoholfree mouthwash and betle-leaf mouthwash; and aquadest as the negative control. There were nine repetitions for each trial material group. The results of the Kruskal Wallis test showed significant differences $(P<0.05)$ between alcohol-free mouthwash containing CPC, alcoholfree mouthwash containing piper betle Linn extract, and aquadest. The result of the Mann Withney test showed that there was a significant difference $(P<0.05)$ between alcohol-free mouthwash containing CPC and alcohol-free mouthwash containing piper betle Linn extract. Alcohol-free mouthwash containing CPC had a wider zone of inhibition than the alcohol-free mouthwash containing betle leaf extract. Conclusion: Inhibition of the alcohol-free mouthwash containing cetylpyridinium chloride on the growth of S.mutans was significantly better than the alcohol-free mouthwash containing piper betle Linn extract.
\end{abstract}

Keywords: cetylpyridinium chloride, betle leaf, mouthwash, Streptococcus mutans.

\begin{abstract}
Karies gigi dan penyakit periodontal merupakan masalah bagi kesehatan gigi dan mulut di masyarakat. Streptococcus mutans dalam plak berperan dalam terjadinya kedua penyakit ini. Pengontrolan plak dapat dilakukan secara kimiawi dengan menggunakan obat kumur. Cetylpyridinium chloride (CPC) dan daun sirih merupakan bahan aktif yang ditambahkan dalam sediaan obat kumur bebas alkohol. Penelitian ini bertujuan untuk melihat apakah terdapat perbedaan daya hambat antara obat kumur bebas alkohol yang mengandung CPC dengan obat kumur daun sirih terhadap pertumbuhan S. mutans. Penelitian ini bersifat eksperimental dengan post-test only control group design. Teknik pengujian daya hambat menggunakan metode difusi cakram Kirby Baurer dengan sampel $S$. mutans. Bahan coba yang digunakan yaitu obat kumur bebas alkohol, dan akuades sebagai kontrol negatif. Jumlah pengulangan pada masing-masing kelompok bahan coba sebanyak 9 kali. Uji Kruskal Wallis menunjukkan perbedaan bermakna $(P<0,05)$ antara obat kumur CPC, obat kumur daun sirih,
\end{abstract}


dan akuades terhadap pertumbuhan S. mutans. Uji Mann-Whitney menunjukkan perbedaan bermakna $(P<0,05)$ antara obat kumur CPC dan obat kumur daun sirih terhadap pertumbuhan S. mutans. Obat kumur CPC memiliki zona hambat lebih besar dibandingkan obat kumur daun sirih. Simpulan: Sediaan obat kumur bebas alkohol yang mengandung cetylpyridinium chloride memilliki daya hambat terhadap pertumbuhan Streptococcus mutans yang lebih tinggi secara bermakna dibandingkan sediaan obat kumur bebas alkohol yang mengandung ekstrak daun sirih.

Kesehatan gigi dan mulut merupakan hal yang penting bagi kesehatan umum seseorang karena mulut yang sehat memungkinkan seseorang untuk makan, berbicara, dan bersosialisasi, tanpa mengalami rasa sakit dan tidak nyaman. ${ }^{1,2}$ Karies gigi dan penyakit periodontal masih menjadi masalah bagi kesehatan gigi dan mulut masyarakat secara umum. ${ }^{3}$

Faktor umum yang menyebabkan terjadinya karies gigi dan penyakit periodontal yaitu plak. ${ }^{4,5}$ Streptococcus mutans (S. mutans) merupakan bakteri gram positif yang berperan dalam pembentukan dan peningkatan akumulasi plak, serta sebagai organisme utama penyebab timbulnya karies. Enzim glucosyl transferase yang dihasilkan oleh $S$. mutans dapat memfasilitasi pembentukan glukan, sehingga membantu perlekatan dan agregasi bakteri lainnya untuk membentuk biofilm plak. ${ }^{6,7}$ Plak yang tidak dibersihkan secara teratur akan mengalami pematangan. Patogenitas yang dihasilkan kompleks bakteri dapat menyebabkan karies, gingivitis, dan periodontitis. Oleh karena itu, pengontrolan plak diperlukan sebagai salah satu upaya untuk memelihara kesehatan gigi dan mulut. ${ }^{8}$

Umumnya kontrol plak dilakukan secara mekanis melalui penyikatan gigi dan pembersihatan interdental, namun kenyataannya terdapt individu yang sulit melakukan kontrol plak secara mekanis dengan baik. Hal ini mungkin terjadi karena kurangnya motivasi dan ketrampilan untuk melakukan kontrol plak secara akurat. Kontrol plak secara mekanis dapat ditunjang melalui pengunaan obat kumur untuk mencapai daerah yang tidak terjangkau dengan penyikatan gigi, dan penggunaan benang gigi. ${ }^{8,9}$
Kandungan dasar obat kumur umumnya terdiri dari air, alkohol, agen pembersih, perasa, dan pewarna. Bahaya penggunaan alkohol dalam obat kumur masih menjadi perdebatan bagi penggunanya. ${ }^{10}$ Penelitian menunjukkan bahwa obat kumur yang mengandung etanol dapat memengaruhi permukaan tambalan resin komposit. ${ }^{11}$ Survei menunjukkan bahwa obat kumur yang mengandung alkohol dapat berkontribusi pada peningkatan risiko kanker mulut. ${ }^{12}$ Adanya pandanganpandangan ini menyebabkan obat kumur bebas alkohol menjadi perhatian dan meningkat di pasaran. Obat kumur bebas alkohol yang terdapat di pasaran, di antaranya mengandung cetylpyridinium chloride (CPC) dan ekstrak daun sirih.

CPC merupakan senyawa amonium kuartenari yang memiliki spektrum antimikroba luas. CPC memiliki sifat dapat larut dalam air, alkohol, kloroform, benzena dan eter. Dari sifat kelarutan ini, CPC dapat dibuat dalam sediaan bebas alkohol. ${ }^{4,13}$ Sirih (piper betle Lynn), merupakan salah satu tanaman tradisional yang dikenal sejak lama di Indonesia sebagai bahan untuk menginang dan menguatkan gigi. ${ }^{14}$ Kandungan ekstrak daun sirih seperti minyak atsiri dengan komponen fenol dan hidroksikavikol memiliki efek antibakteri. ${ }^{15}$

\section{METODE PENELITIAN}

Jenis penelitian ini yaitu eksperimental laboratorium, dengan rancangan penelitian post-test only control group design. Penelitian dilakukan di Laboratorium Universitas Hasanuddin Fakultas Kedokteran Makassar pada bulan Oktober 2012. Sampel yang digunakan yaitu biakan murni 
S. mutans dengan bahan coba obat kumur bebas alkohol yang mengandung CPC dan obat kumur yang mengandung ekstrak daun sirih, serta aquades sebagai kontrol negatif. Jumlah pengulangan pada masing-masing bahan coba sebanyak 9 kali, yang didapat dengan menggunakan rumus Frederer: $\{(\mathrm{t}-$ 1).(n-1) $\geq 15\}$. Pengujian daya hambat bakteri $S$. mutans dilakukan melalui metode difusi cakram Kirby Baurer.

Langkah kerja penelitian ialah: sterilisasi alat, pembuatan media brain heart infusion broth (BHI-B), pembuatan media Mueller Hinton agar (MHA), pembiakan spesimen, pengujian daya hambat bakteri

\section{HASIL PENELITIAN}

Hasil penelitian yang dilakukan pada tiga jenis bahan coba menunjukkan zona hambat pada setiap cakram yang dicelupkan obat kumur yang mengandung CPC dan obat kumur daun sirih, sedangkan cakram yang dicelupkan aquades sebagai kontrol negatif tidak ditemukan zona hambat (Gambar 1). Diameter zona hambat bahan coba diukur dalam satuan mm (Tabel 1).

Hasil uji normalitas pada Tabel 2 menunjukkan data zona hambat obat kumur yang mengandung CPC memiliki $P>0,05$, maka data CPC terdistribusi normal. Zona hambat obat kumur daun sirih memiliki $P<$ 0,05, maka data zona hambat daun sirih tidak terdistribusi normal. Oleh karena itu, pengujian statistik pada penelitian ini menggunakan uji statistik non-parametik untuk memenuhi asumsi data penelitian yang tidak terdistribusi normal.

Hasil uji Kruskal-Wallis menunjukkan mean ranking dari setiap bahan coba $\mathrm{CPC}$, daun sirih dan aquades secara berturut-turut yaitu 23,00, 14,00, dan 5,00 dengan perbedaan yang bermakna $0,000(P<0,05)$.

Hasil uji Mann-Whitney U menunjukkan mean rank obat kumur yang mengandung CPC lebih tinggi dari pada obat kumur yang mengandung ekstrak daun sirih $5,00(P=0,00)$.
Tabel 1. Rerata dan Standard Deviasi zona hambat bahan coba terhadap bakteri $S$. mutans.

\begin{tabular}{cccc}
\hline Bahan coba & N & $\overline{\boldsymbol{x}}$ & SD \\
\hline I & 9 & 34,69 & 3,10 \\
II & 9 & 11,57 & 3,51 \\
III & 9 & 0,00 & 0,00 \\
\hline
\end{tabular}

Keterangan:

I : Obat kumur yang mengandung CPC

II : Obat kumur yang mengandung daun sirih

III : Aquades (kontrol negatif)

$\mathrm{N}$ : Jumlah perlakuan tiap bahan coba

$\bar{x} \quad$ : Rerata (mm)

SD : Standar Deviasi

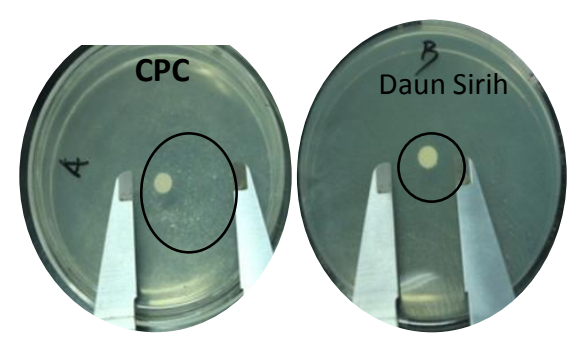

Gambar 1. Zona hambat obat kumur yang mengandung CPC dan obat kumur yang mengandung daun sirih terhadap pertumbuhan S. mutans.

Tabel 2. Hasil uji normalitas data bahan coba CPC dan daun sirih menggunakan uji Kolmogorov-Smirnov.

\begin{tabular}{cc}
\hline Bahan coba & $\boldsymbol{P}$ \\
\hline I & 0,200 \\
II & 0,000 \\
\hline Keterangan:
\end{tabular}

Tabel 3. Hasil uji Kruskal Wallis antara bahan coba.

\begin{tabular}{lccc}
\hline \multicolumn{2}{c}{ Bahan coba } & Mean rank & $\boldsymbol{P}$ \\
\hline \multicolumn{4}{c}{ I } \\
II & 23,00 \\
III & 14,00 & 0,000 \\
\hline \multicolumn{2}{c}{ Keterangan: } \\
P $\quad$ : Signifikansi $(P<0,05)$ \\
I $\quad$ : Obat kumur yang mengandung CPC \\
II $\quad$ : Obat kumur yang mengandung daun sirih. \\
III $\quad:$ Akuades (kontrol negatif)
\end{tabular}


Tabel 4. Hasil uji Mann Whitney-U antara bahan coba CPC, daun sirih, dan akuades.

\begin{tabular}{ccc}
\hline Bahan coba & Mean rank & $\boldsymbol{P}$ \\
\hline I & 23,00 & \\
II & 14,00 & 0,000 \\
III & 5,00 & \\
\hline
\end{tabular}

Keterangan:

$\mathrm{P} \quad$ : Signifikansi $(\mathrm{P}<0,05)$

I : Obat kumur yang mengandung CPC

II : Obat kumur yang mengandung daun sirih

\section{BAHASAN}

Perbandingan daya hambat obat kumur yang mengandung CPC dengan obat kumur daun sirih terhadap pertumbuhan $S$. mutans diteliti dengan menggunakan metode difus cakram Kirby Baurer disertai dengan akuades sebagai kontrol negatif. Hasil penelitian ini menunjukkan bahwa zona hambat terdapat pada obat kumur yang mengandung CPC dan obat kumur yang mengandung ekstrak daun sirih, sedangkan pada akuades tidak terdapat zona hambat.

Hasil rerata besar zona daya hambat dari setiap bahan coba CPC daun sirih dan akuades secara berturut-turut yaitu 34,69 $\mathrm{mm}(\mathrm{SD} \pm 3,10)$ 11,57 mm (SD $\pm 3,51)$, dan $0 \mathrm{~mm}$. Hasil uji Kruskal-Wallis menunjukkan mean ranking dari bahan coba $\mathrm{CPC}$ lebih tinggi dari pada daun sirih dan aquades $(P<0,05)$. Data ini menunjukkan daya hambat terhadap bakteri $S$. mutans paling besar dimiliki oleh obat kumur yang mengandung CPC dibandingkan dengan obat kumur yang mengandung ekstrak daun sirih dan akuades. Hasil penelitian ini sejalan dengan penelitian Akande et al. ${ }^{16}$ yang menunjukkan bahwa obat kumur yang mengandung CPC memiliki efek antibakteri terbesar dari obat kumur yang mengandung senyawa fenol dan gliserin/ triklosan. Efek antibakteri tersebut dilakukan pada bakteri rongga mulut berikut: Staphylococcus aureus, Streptococcus pyogenes, S. mutans, Helicobacter pylori, Actinomyces viscosus, Candida albicans, dan Porphyromnas gingivalis.

Penelitian secara in vitro oleh Schaeffer et al. ${ }^{17}$ menunjukkan obat kumur yang mengandung $0,075 \%$ CPC bebas alkohol dapat menghambat $99,9 \%$ lebih bakteri $S$. mutans. Penelitian secara in vivo oleh Sreenivasan et al. $^{18}$ menunjukkan bahwa obat kumur yang mengandung 0,05\% CPC dapat menghambat $90 \%$ lebih bakteri dalam plak gigi. Hasil yang didapatkan pada penelitian ini sesuai dengan kedua hasil penelitian di atas yang menunjukkan adanya aktifitas antibakteri dari CPC dengan zona hambat yang luas, melebihi zona hambat obat kumur yang mengandung ekstrak daun sirih. Data ini sesuai dengan teori yang mengatakan bahwa CPC memiliki kemampuan untuk mengadsorpsi muatan negatif dari bakteri, meningkatkan permeabilitas dinding sel bakteri, menurunkan metabolisme sel, mengurangi perlekatan bakteri pada permukaan gigi, serta menghambat pertumbuhan sel. ${ }^{4}$

Obat kumur yang mengandung ekstrak daun sirih menunjukkan adanya zona hambat terhadap bakteri S. mutans. Hasil penelitian ini sejalan dengan penelitian Pratiwi $^{19}$ mengenai studi mikroskopik antimikroba ekstrak kasar air daun sirih terhadap bakteri $S$. mutans dengan menggunakan transmission electron microscopy (TEM), thin layer chromatography (TLC) dan gas chromatography mass spectrometry (GCMS). Hasil penelitian tersebut menunjukkan ekstrak kasar air daun sirih menyebabkan kerusakan dari plasma sel dan nukloid, serta mengurangi produksi asam dari S. mutans.

Hasil uji Mann-Whitney U menunjukkan mean rank obat kumur yang mengandung CPC 14,00, sedangkan mean rank obat kumur yang mengandung ekstrak daun sirih 5,00 dengan $P=0,00$. Berdasarkan hasil ini peneliti mengasumsikan bahwa perbedaan daya hambat kedua bahan coba dipengaruhi oleh beberapa faktor, antara lain: komposisi, bentuk bahan aktif, dan kandungan bahan antibakteri.

Komposisi obat kumur yang mengandung CPC antara lain mengandung fluor sedangkan komposisi obat kumur daun sirih tidak mengandung fluor. Penelitian oleh Jamilah ${ }^{20}$ mengenai pasta gigi yang mengandung fluor dengan beberapa 
konsentrasi memperlihatkan bahwa secara in vitro fluor menunjukkan daya antibakteri yaitu pada pasta gigi fluor dengan konsentrasi $100 \%$, 10\%, dan 1\%, dan tidak pada konsentrasi $0,1 \% .{ }^{20}$ Dengan demikian, penulis berasumsi bahwa kandungan flour yang terdapat dalam obat kumur yang mengandung CPC memungkinkannya memiliki daya hambat yang lebih besar dibandingkan obat kumur yang mengandung ekstrak daun sirih. Konsentrasi flour yang terkandung dalam obat kumur yang mengandung CPC tidak dicantumkan; oleh karena itu, belum bisa dipastikan peran antibakteri fluor dalam obat kumur ini.

Kekurangan dalam penelitian ini yakni bahan coba CPC yang digunakan merupakan obat kumur dalam bentuk sediaan paten yang terdapat di pasaran. Hal ini menyebabkan kadar serta kandungan yang terdapat dalam obat kumur tersebut dan obat kumur daun sirih tidak dapat dikendalikan. Data hasil penelitian obat kumur yang mengandung daun sirih belum terdistribusi normal; hal ini disebabkan jumlah pengulangan pada sampel masih kurang.

\section{SIMPULAN}

Dari hasil penelitian dapat disimpulkan bahwa daya hambat terhadap pertumbuhan Streptococcus mutans dari sediaan obat kumur bebas alkohol yang mengandung cetyl-pyridinium chloride lebih tinggi secara bermakna dibandingkan obat kumur bebas alkohol yang mengandung ekstrak daun sirih.

\section{SARAN}

Disarankan untuk menguji efek lidah buaya terhadap bakteri lain yang dapat menimbulkan masalah kesehatan gigi dan mulut.

\section{DAFTAR PUSTAKA}

1. Ireland $\mathbf{R}$, editor. Clinical text book of dental hygiene and therapy (First Edition). Oxford; Ames, Iowa:
Blackwell Munksgaard; 2006. p.137.

2. PDGI. 2011. Berita-Menteri kesehatan mendukung program 3L PDGI [homepage on the Internet]. Nodate [cited 2012 May 16]. Available from: http://www.pdgi.or.Id/news/detail/ment eri-kesehatan-mendukung-program-31pdgi.

3. World Health Organization. Oral health (key fact) [homepage on the Internet]. 2011. [cited 2012 May 16]. Available from: http://www.who.int/mediacentre/factshe ets/fs318/en/index.html.

4. Yagiela JA, Dowd FJ, Neidle EA. Pharmacology and Therapeutics for Dentistry (Fifth Edition). St.Louis: Mosby; 2005.

5. Chismirina S, Gani BA, Subhaini. Manifestasi molekuler biofilm streptococcus mutans sebagai organisme utama penyebab karies. Cakradonya dent J. 2010;2(1):83-158.

6. Gani BA. Sifat asidogenik dan asidurik Streptococcus mutans sebagai bakteriostatik mikrobiota patogen rongga mulut. Cakradonya dent. F 2010;2(1):128-34.

7. Bowen WH, Koo H. Biology of streptococcus mutans-derived glucosyltransferase; role in extra-cellular matrix formation of cariogenic biofilm. Caries Res. 2011;45(1):69-86.

8. JoAnn R. Gurenlian. The role of dental plaque biofilm in oral health. J Dent Hyg. 2007(supplement);4-12.

9. Mitchell L, Mitchell DA, McCaul L. Oxford Handbook of Clinical Dentistry (Fifth Edition). Oxford: Oxford University Press; 2009.

10. Farah CS. Moutwashes. Aust Prescr. 2009;32:162-4.

11. Natalina. Mouthrinses and potential for harm to oral health. Dentika Dent J. 2010;15(2):198-201.

12. Indriani DJ, Triaminingsih S, Lucky, $N$ Nurvanita, Yuliati N. Effect of ethanol in moutwashes on the surface hardness of a dental resin composite material. Padjadjaran Dent J. 2009;21(1):8-13.

13. Sarah P, Trevor F, David J, Ian M, Julia H, Philip W. Efficacy of two alcoholfree cetylpyridinium chloride moutwashes-a randomized doubleblinded crossover study. J Clin Periodontol. 2008;35:230-5. 
14. Damayanti R, Mulyono. Khasiat dan Manfaat Daun Sirih: Obat Mujarab dari Masa ke Masa. Jakarta: Agro Media Pustaka; 2005.

15. Chakraborty D, Shah B. Antimicrobial, anti-oxidative and anti-hemolytic activity of piper betle leaf extracts. Int $\mathbf{J}$ Pharmacy and Pharmaceutical Sc. 2011;3:192-9.

16. Akande OO, Alada ARA, Aderinokun GA, Ige AO. Efficacy of different brands of mouth rinses on oral bacterial load count in healthy adults. AJBR. 2004:7;125-8.

17. Schaeffer LM, Szewczyk G, Nesta J, Vandeven $M$, Du-Thumm $L$, Williams MI, et al. In vitro antibacterial efficacy of cetylpyridinium chloride-containing mouthwashes. J Clin Dent. 2011;22(6):183-6.

18. Sreenivasan PK, Haraszthy VI, Zambon JJ. Antimicrobial efficacy of $0,05 \%$ cetylpyridinium chloride mouthrinses. Letters in applied microbiology. 2012;56:14-20.

19. Pratiwi R. Perbedaan daya hambat terhadap streptococcus mutans dari beberapa pasta gigi yang mengandung herbal. Maj. Ked. Gigi. (Dent. J.) 2005;38(2):64-7.

20. Jamilah M. Perbandingan efektifitas pasta gigi yang mengandung ekstrak daun sirih dan flour terhadap pertumbuhan koloni Streptococcus mutans [skripsi]. Medan; Fakultas Kedokteran Gigi USU; 2010. 